\title{
Combined analysis of transcriptome studies of bovine endometrium during the preimplantation phase and comparison to results from ovine and porcine preimplantation endometrium
}

\author{
Stefan Bauersachs \\ ETH Zurich, Animal Physiology, Institute of Agricultural Sciences, Department of Environmental \\ Systems Science, Universitaetstrasse 2 / LFW B 58.1, 8092 Zurich, Switzerland
}

\begin{abstract}
Summary
Transcriptome studies of the bovine endometrium during early pregnancy and during the estrous cycle have been performed using DNA microarrays and RNA sequencing to identify genes associated with establishment and maintenance of pregnancy. The results of these studies are reviewed and the identified differentially expressed genes (DEG) are compared to define the overlaps between studies and technical platforms. Good overlaps were found for upregulated genes between different days of the preimplantation phase and between microarrays and RNA-Seq. In contrast, overlaps for downregulated genes were clearly lower between days but also between platforms. Possible causes are discussed. All DEG of the analyzed studies were summarized and a combined functional annotation analysis was performed. Gene expression of selected genes found as important for maternal recognition of pregnancy and implantation in sheep was compared between bovine and ovine endometrium. Furthermore, DEG in bovine endometrium were compared to DEG found in porcine endometrium on Day 14 of pregnancy, revealing significant similarities in differential endometrial gene expression in cattle and pigs.
\end{abstract}

\section{Introduction}

The successful development of the bovine conceptus during the preimplantation phase is strongly dependent on the maternal environment, which is mainly controlled by the ovarian steroid hormones. The most important steroid hormone for uterine receptivity is progesterone (P4) (Spencer \& Bazer 2002, Bazer et al. 2008). The importance of P4 for preimplantation conceptus growth and development in cattle has been shown in several studies with elevated P4 in the post-conception period (Clemente et al. 2009, Forde et al. 2009), exogenous supplementation of P4 and induction of low circulating P4 (Forde et al. 2011a), P4 treatment to compensate asynchronous embryo transfer (ET) (Geisert et al. 1991), and other studies using asynchronous ET as a model for the study of endometrial receptivity (Ledgard et al. 2012). On the other hand, in ruminants the maintenance of the production of progesterone is dependent on the embryonic pregnancy recognition signal interferon tau (IFNT), which prevents luteolysis (Thatcher et al. 1989) and modifies endometrial gene expression. Since expression of type I and/or type II interferons (IFNs) has been found in many mammals during the pre- and periimplantation phase, modulation of endometrial gene expression by these cytokines probably plays a significant role not only for pregnancy recognition in ruminants but for embryo implantation in general (Bazer 
et al. 2009). The complex interplay of P4, IFNT, and other conceptus and endometrium derived factors, such as prostaglandins, is the basis for proper conceptus development in preparation for implantation and placentation (Dorniak et al. 2013).

In the last decade, many holistic studies of gene expression in the bovine endometrium have been performed for different stages of the estrous cycle and the pre- and periimplantation period (reviewed in Forde \& Lonergan 2012, Ulbrich et al. 2013), showing very complex gene expression changes underlying the complex physiological changes in this tissue. In a previous study, we compared the results of a number of transcriptome studies performed on different days of early pregnancy and found good agreement even though different technical platforms and different gene annotations were used and the studies were performed in different laboratories (Bauersachs et al. 2012). In this review the most relevant endometrial transcriptome studies performed to date are summarized and the overlaps between studies and technological platforms are characterized. In addition, results are compared to findings in ovine and porcine endometrium during the preimplantation phase.

\section{Comparison of differentially expressed genes identified in transcriptome studies in bovine endometrium during the preimplantation phase}

A considerable number of transcriptome studies using DNA microarrays and more recently RNA sequencing (RNA-Seq) have been performed for different days of the preimplantation phase in bovine endometrium ranging from Day 13 to Day 18 of pregnancy. Although these studies have been performed from different groups, by the use of different technical platforms, and with different approaches for data analysis, a consistent overlap was found for the studies on Days 15, 16, 17 and 18 of pregnancy by the use of Gene Set Enrichment Analysis (GSEA) (Bauersachs et al. 2012). The results of a new comparison of the identified differentially expressed genes (DEG) are shown in Fig. 1. The comparison was based on data from the very first transcriptome studies of bovine endometrium using a combination of subtracted cDNA libraries and cDNA microarrays (Bauersachs et al. 2006, Klein et al. 2006), studies performed with the Affymetrix Bovine Genome Array (Forde et al. 2011b, Bauersachs et al. 2012), one study using Agilent microarrays (Walker et al. 2010), and in addition, studies implementing RNA sequencing (Bauersachs \& Wolf 2012, Forde et al. 2012). Although the lists of DEG provided with the individual publications were very heterogeneous regarding gene or transcript identifiers, if provided at all, gene annotation was updated to the same state and to get comparable gene identifiers (gene symbols). Altogether, more than 3300 genes were found as differentially expressed (Supplemental Table 1) on the studied days of pregnancy. The comparison of the lists of DEG did not show an overlap of the genes identified on Day 13 of pregnancy (Forde et al. 2012) with the DEG obtained from all later time points, neither for upregulated nor for downregulated genes (Fig. 1, top and bottom left). In concordance with the results from GSEA, relatively good overlaps were found for the upregulated genes, e.g., 288 genes found as upregulated on Day 15 (Illumina data set, Fig. 1, top left) and on at least one of the following time points and only 72 genes were found only on Day 15. Similarly for Day 16 (Forde et al. 2012), 198 genes were found as upregulated on Day 16 and on at least one other time point in contrast to only 31 found solely for Day 16 . For the 540 genes found as upregulated on Day 17 of pregnancy (Walker et al. 2010), 304 genes were also identified in one or more of the other studies. Similar overlaps were found for the comparison of the DEG derived from the microarray studies (Fig. 1, top right). In contrast, the overlap for the downregulated genes was much lower, particularly for those obtained for Days 16 and 17 of the microarray studies (Walker et al. 2010, Forde et al. 2011b) (Fig.1, bottom right). 

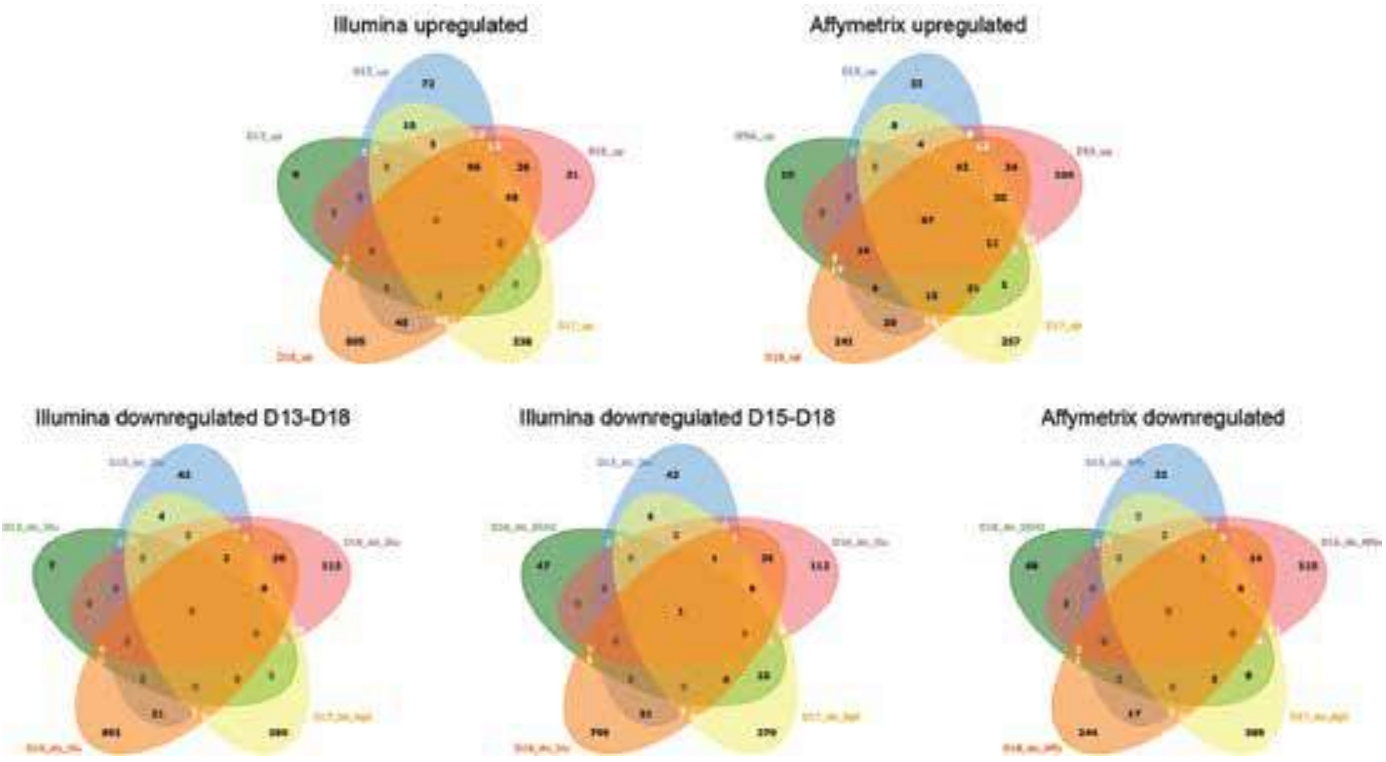

Fig. 1. Overlap of differentially expressed genes found in transcriptome studies for different days of the preimplantation phase. Venn diagrams were produced based on gene symbols of the reannotated gene lists using the web tool jquery.venny. D: Day; IFNA: interferon alpha; Agil: Agilent; SSH: Suppression Subtractive Hybridization; SSH2: Bauersachs et al. 2006.
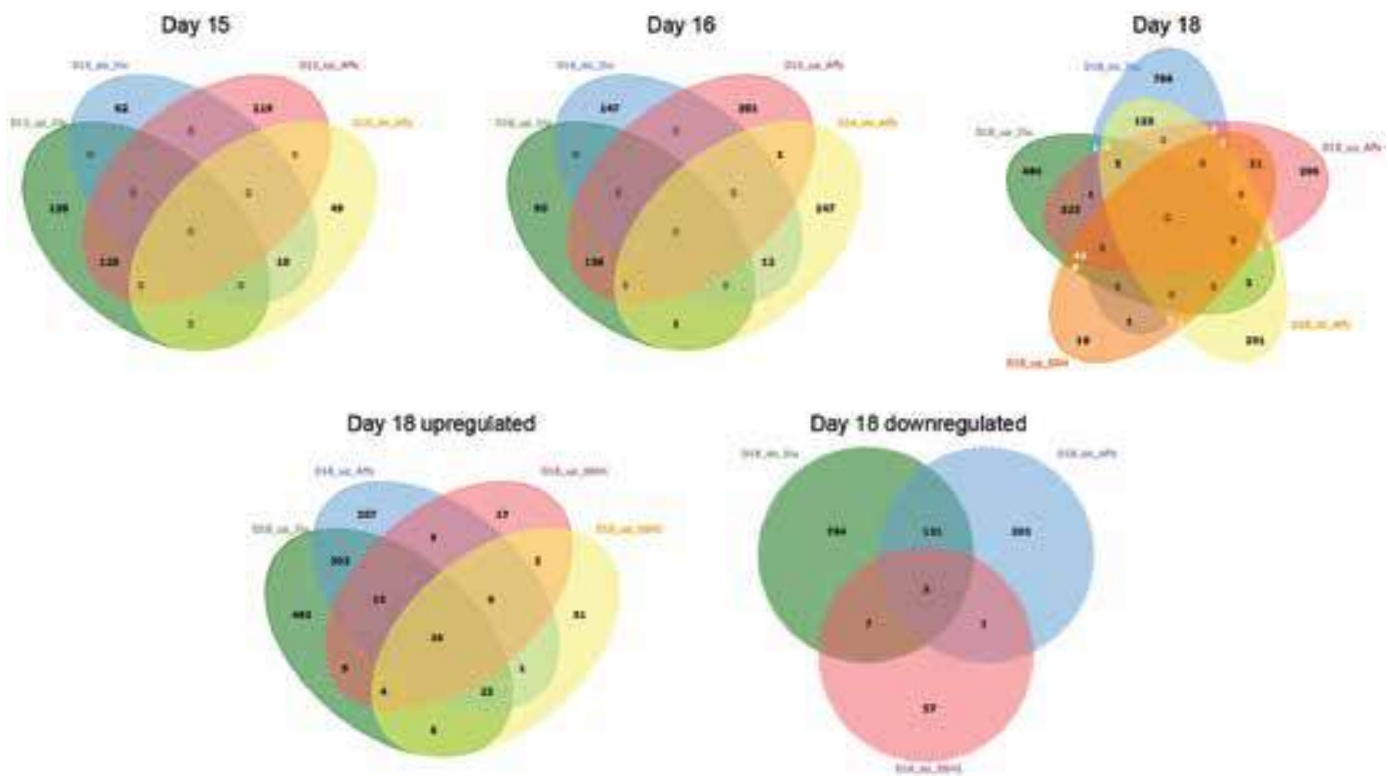

Fig. 2. Overlap of differentially expressed genes for different technological platforms. Venn diagrams were produced based on gene symbols of the reannotated gene lists using the tool jquery.venny. D: Day; SSH: Suppression Subtractive Hybridization; SSH1: Klein et al. 2006; SSH2: Bauersachs et al. 2006.

The comparison of RNA-Seq and microarrays showed clear lower overlap for downregulated genes. Fig. 2 shows a comparison of the different technology platforms for the days where studies with different platforms have been performed. Also between platforms, the overlap 
of DEG was clearly lower for the downregulated genes. A comparison of the median of the corrected P-values for downregulated and upregulated genes revealed that P-values were better for upregulated genes compared to the downregulated genes for all studies (Table 1). In general, the main limitations for such comparisons are probably differences in statistical analysis of gene expression data, limited numbers of investigated biological replicates, and gene annotation, which is very dynamic, i.e., changes with time. For example, in the Agilent microarray study of Day 17 of pregnancy (Walker et al. 2010), a false discovery rate (FDR) of $5 \%$ was used. In consideration of the number of DEG found in this study, about 60 genes are likely to be false positives ( $5 \%$ of 1189 ).

Table 1. Median P-values for downregulated and upregulated genes

\begin{tabular}{lccc}
\hline Study & Downregulated & Upregulated & Replicates \\
\hline Day 15 Illumina & 0.00035 & 0.00012 & 3 \\
Day 15 Affymetrix & 0.0334 & 0.0140 & 3 \\
Day 16 Illumina & 0.0003401 & 0.0000006 & 5 \\
Day 16 Affymetrix & 0.018 & 0.002 & 5 \\
Day 17 Agilent & 0.0080 & 0.0037 & $10,12^{*}$ \\
Day 18 Illumina & 0.00057 & 0.00014 & 4 \\
Day 18 Affymetrix & 0.0101 & 0.0046 & 4 \\
\hline
\end{tabular}

*10 cyclic and 12 pregnant cows

However, the results of GSEA show that a clear enrichment towards the expected end of the ranked data sets for Days 15 and 18 of pregnancy is also present for the downregulated genes (Fig. 3). This indicates that expression differences and corrected P-values of a considerable part of the "nonoverlapping" genes, i.e., DEG found in only one study, are near by but below the thresholds set in the individual studies. In addition, it is also likely that some of the DEG show differential expression only during a distinct and short phase of early pregnancy and therefore were found only once.

Despite of the limitations of the technical platforms for transcriptome analyses, limited numbers of biological replicates in most studies and different strategies and thresholds for statistical analysis, the performed studies revealed first changes in the endometrial transcriptome on Day 13 of pregnancy (Forde et al. 2012), substantial differences on Day 15 (Bauersachs et al. 2012) and increasing numbers of DEG up to Day 18 of pregnancy. In our own studies, we analyzed also Day 12 of pregnancy but did not find significant changes in whole endometrial tissue samples (S Bauersachs, H D Reichenbach, H Blum \& E Wolf 2008, unpublished observations). Particularly for Days 15 and 16, more upregulated than downregulated genes were found, probably due to the effects of IFNT resulting predominantly in activating responses.

\section{Functional groups overrepresented in the identified differentially expressed genes}

A summarization of the DEG found in the analyzed studies is shown in Supplemental Table 1 with the frequency with which the genes have been found as well as the corresponding studies. For some gene families, similar regulation for all or almost all members of the family was observed. Some members of such gene families were only identified in one or two studies. Details are shown in Table 2 for one example, the homeobox A (HOXA), HOXB and HOXC gene 


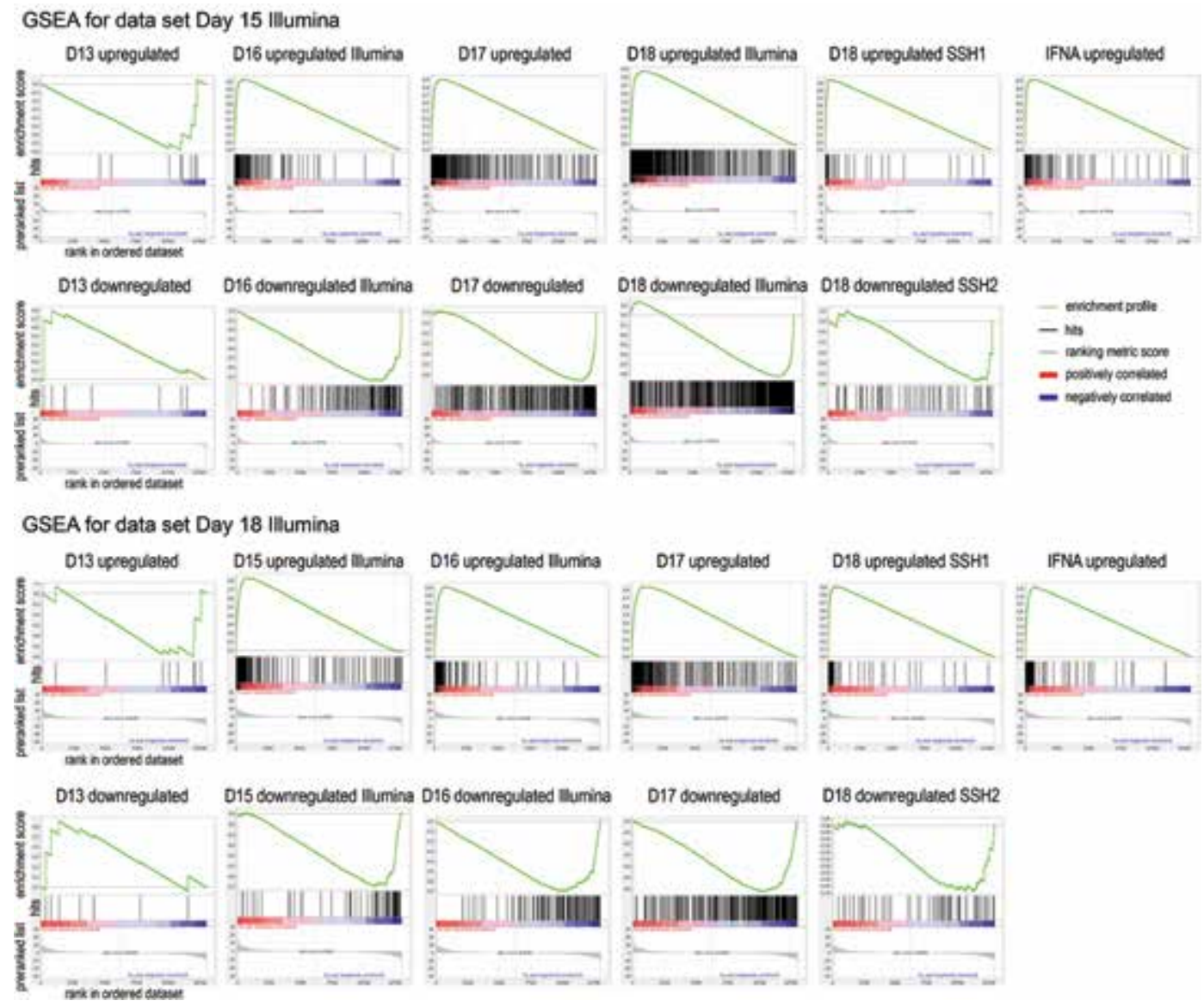

Fig. 3. Comparison of the RNA sequencing data sets for Days 15 and 18 of pregnancy with the sets of differentially expressed genes of the other studies. Gene set enrichment analysis (Subramanian et al. 2007) was performed for preranked (based on a score calculated from fold change and P-value) lists of detectable genes in the RNA-Seq analysis for Days 15 and 18 of pregnancy, respectively, in comparison to the sets of differentially expressed genes of the other studies. D: Day; IFNA: interferon alpha; SSH: Suppression Subtractive Hybridization; SSH1: Klein et al. 2006; SSH2: Bauersachs et al. 2006.

families. All members of these HOX families show lower expression in pregnant endometrium from Day 15 through Day 18. These homeobox transcription factors have been shown to play a role in regulation of cell differentiation of various cell types such as hematopoietic cells (Magli et al. 1997), endothelial cells (Minten et al. 2013), and normal epithelial and tumor cells (Venhoranta et al. 2013). Downregulation of transcription was observed for the complete HOXB gene cluster, but also for 4 members of the HOXA cluster and two genes of the HOXC family (Supplemental Table 1). So far, only upregulation of HOXA10 and HOXA11 has been shown in murine and human endometrium during implantation (Eun Kwon \& Taylor 2004). However, the downregulation of HOX genes could be associated with a differentiation status of endometrial cells needed for the preparation for conceptus implantation. A role of HOXB genes in context of morphogenesis has been found, for example, also in the lung of the mouse 
Table 2. Summary of differentially expressed HOX genes

\begin{tabular}{lllcll}
\hline $\begin{array}{l}\text { Gene } \\
\text { symbol }\end{array}$ & $\begin{array}{l}\text { Gene } \\
\text { description }\end{array}$ & Bta Gene ID & $\begin{array}{c}\text { Hsa Gene } \\
\text { ID }\end{array}$ & $\begin{array}{l}\text { Frequency } \\
\text { Study(ies) }\end{array}$ \\
\hline HOXA3 & homeobox A3 & 509991 & 3200 & 1 & D18 down Illu \\
HOXA4 & homeobox A4 & 538865 & 3201 & 1 & D16 down Affy \\
HOXA6 & homeobox A6 & 100848736 & 3203 & 1 & D18 down Illu \\
HOXA7 & homeobox A7 & 615851 & 3204 & 1 & D15 down Illu \\
HOXB2 & homeobox B2 & 616129 & 3212 & 4 & D16 down Illu,D17 down,D18 \\
& & & & down Affy, D18 down Illu \\
HOXB3 & homeobox B3 & 618214 & 3213 & 1 & D18 down Illu \\
HOXB4 & homeobox B4 & 768240 & 3214 & 2 & D16 down Illu,D18 down Affy \\
HOXB5 & homeobox B5 & ENSBTAG00000045835 & 3215 & 2 & D15 down Affy,D18 down Affy \\
HOXB6 & homeobox B6 & 100337380 & 3216 & 4 & D15 down Affy,D15 down \\
& & & & & Illu,D18 down Affy,D18 down \\
HOXB7 & homeobox B7 & 281820 & 3217 & 2 & D16 down Illu,D18 down Affy \\
HOXB8 & homeobox B8 & 785855 & 3218 & 3 & D15 down Affy,D16 down \\
& & & & Affy, D18 down Affy \\
HOXC10 & homeobox C10 & 100847795 & 3226 & 1 & D17 down \\
HOXC6 & homeobox C6 & 317660 & 3223 & 1 & D17 down \\
\hline
\end{tabular}

fetus via regulation of ECM expression of tenascin C (TNC) and modulation of FGF10 spatial expression (Volpe et al. 2007). In concordance with this finding, DAVID Functional Annotation Clustering revealed overrepresentation of functional terms related to cell differentiation such as "tissue morphogenesis" and "epithelium development" (Supplemental Table 2a).

Members of the WNT signaling pathway were also assigned to these or similar categories and were likewise predominantly downregulated (frizzled family receptors [FZD3, FZD4, FZD5, FZD10], wingless-type MMTV integration site family members [WNT5A, WNT6, WNT9A], WNT1 inducible signaling pathway protein genes 1 and 2 [WISP1, WISP2]). Downregulation of WNT signaling by progesterone has been shown in ovine and human endometrium (Satterfield et al. 2008, Wang et al. 2009).

Another group of genes, which were primarily downregulated, were collagen genes (20 genes, for details see Supplemental Table 1), mainly at later time points of the preimplantation phase. This could be due to preparation of the endometrium for the next estrus during the follicular phase in the cyclic control animals. A second group of genes probably related to extracellular matrix (ECM) remodeling was the ADAM metallopeptidase domain and the ADAM metallopeptidase with thrombospondin type 1 motif gene family, which was also mainly downregulated. Overrepresentation of ECM-related functional categories for the genes downregulated in pregnant endometrium was confirmed with the results from DAVID Functional Annotation Clustering (Supplemental Table 2a).

The upregulated genes were, in addition to immune response-related genes, enriched for genes coding for mitochondrial proteins such as mitochondrial ribosomal proteins, ATP synthases, NADH dehydrogenase subunits, and a number of other mitochondrial enzymes. However, most of the overrepresented functional categories were related to various immune response functions and processes (Supplemental Table 2b). 


\section{Comparison to gene expression in ovine endometrium for genes associated with maternal recognition of pregnancy and conceptus implantation}

The model of maternal recognition of pregnancy (MRP) in ruminants, mainly established based on studies in sheep, comprises upregulation of the transcriptional repressor interferon regulatory factor 2 (IRF2) in the luminal epithelium (LE). IRF2 suppresses the upregulation of ESR1 and OXTR eventually leading to the prevention of the release of PGF2a (Spencer et al. 2007). In bovine endometrium, IRF1 and IRF3 to IRF9, but not IRF2, were found as upregulated in pregnant animals. IRF2 expression was detected in the transcriptome studies but with similar levels in cyclic and pregnant endometrium. It is possible that upregulation of IRF2 also occurs in bovine endometrium, but specifically in the LE and thus not detectable in the analysis of whole endometrial tissue samples. Like in sheep, ESR 1 and OXTR are also repressed in bovine endometrium.

In sheep, a number of genes have been shown to be important for conceptus attachment and implantation, such as secreted phosphoprotein 1 (osteopontin, SPP1), galectin 15 (LGALS15), and glycosylation-dependent cell adhesion molecule 1 (GLYCAM1) (Spencer et al. 2004). SPP1 is also upregulated in pregnant bovine endometrium (Supplemental Table 1; Days 15, 17 and 18). The putative ortholog of ovine LGALS15 is not expressed in bovine endometrium. However, other members of the galectin gene family are expressed and LGALS7 and LGALS9 have been found as upregulated in pregnant endometrium (LGALS9 from Day 15 to 18). Localization of LGALS9 mRNA expression in bovine endometrium has been shown in luminal epithelium (Bauersachs et al. 2006) similar to the localization found in human endometrium (Popovici et al. 2005). These findings indicate that other galectins may have a similar function in conceptus attachment as LGALS15 in ovine endometrium. GLYCAM1 was not found to be expressed in bovine endometrium consistent with data from the UniGene database where 215 expressed sequence tags (ESTs) are listed, which were almost exclusively found in the mammary gland with only 3 ESTs from the liver. Like the human LGALS15 ortholog, GLYCAM1 is a pseudogene in humans. The expression of another protein relevant for the process of conceptus attachment, mucin 1 (MUC1), is downregulated in the LE in ovine endometrium during the preimplantation phase (Johnson et al. 2001). In bovine endometrium, MUC1 was detected but not downregulated in pregnant endometrium. However, since the downregulation is specific for the LE this is probably hidden in the analysis of whole endometrial tissues.

Integrins have also been shown to be involved in the attachment of trophoblast and LE cells. A constitutive expression has been shown in ovine trophoblast and endometrial cells for the integrin subunits alpha (ITGAV, ITGA4, ITGA5) and beta (ITGB1, ITGB3 and ITGB5) (Johnson et al. 2001). In contrast, a number of integrin genes are differentially expressed in bovine endometrium, at least at the mRNA level. ITGA3, ITGA4, ITGA10, ITGAV, and ITGB6 were found as upregulated and ITGA7, ITGAE, and ITGB8 as downregulated (Supplemental Table 1). Some of these integrin genes show a similar regulation in porcine endometrium on Day 14 of pregnancy, namely ITGA4, ITGAV, and ITGB6 (Samborski et al. 2013a). Overall, this comparison indicates that there are similarities but also distinct differences even between closely related species such as cattle and sheep.

\section{Comparison to results from porcine endometrium on Day 14 of pregnancy}

Since there are some similarities between cattle and pigs during the preimplantation phase, we recently performed a comparison of results from Day 18 of pregnancy in bovine endometrium (Bauersachs et al. 2012) to Day 14 of pregnancy in porcine endometrium (Samborski et al. 
2013a). This comparison of the bovine Day 18 Affymetrix microarray data set and the porcine Day 14 RNA-Seq data set revealed a total overlap of 239 genes out of 1512 porcine genes, where 34 genes were found as downregulated in both studies, 180 were upregulated in both studies, and 25 genes showed contrary changes (Samborski et al. 2013a). Using all DEG of the bovine studies for Days 15, 16, 17 and 18 (omitting genes upregulated on one and downregulated on other days of pregnancy), the total overlap was 505 out of 1512 porcine genes (Supplemental Table 3). In both studies, 124 genes were found as downregulated and 292 as upregulated, respectively. Eighty-nine of the genes found in both species showed contrary changes. Both comparisons revealed many more overlapping genes than expected by chance. In addition, more than $80 \%$ of the overlapping genes showed similar regulation in both species further confirming the specificity of the observed overlap.

DAVID Functional Annotation Clustering for the genes upregulated in both species mainly revealed functional terms related to immune response as overrepresented (Supplemental Table 4a). In addition, genes involved in regulation of apoptosis were enriched in the upregulated genes. Overrepresented functional categories for the genes downregulated in both species were, for example, "extracellular matrix", "calcium ion binding", and "transcription factor activity" (CREB3L4, ESR1, HOXA3, HOXB5, HOXB6, HOXB8, NR2F6, SPDEF, TCF7L1, ZNF202) (Supplemental Table 4b). Interestingly, some members of the HOX family were also downregulated in porcine endometrium on Day 14 of pregnancy as well as on Day 12 of pregnancy (HOXA3, HOXB2, HOXB3, HOXB4, HOXB5, HOXB6, HOXB8) (Samborski et al. 2013b). A number of overrepresented functional terms were also found for the genes with opposite regulation, such as "extracellular region", "cell adhesion", "cytoplasmic membranebounded vesicle", "extracellular matrix", and "cell motion" (Supplemental Table 4c).

\section{Strategies and approaches to obtain deeper insights into processes related to establishment and maintenance of pregnancy}

All of the above-described studies have been performed using complete endometrial tissue samples. However, this tissue is highly complex and contains various cell types, such as luminal and glandular epithelial (GE) cells, stromal cells, endothelial cells and a variety of immune cells. This results in an average of gene expression over all endometrial cells, which could hide cellspecific changes or neutralize opposite changes in different cell types. Incorrect conclusions with respect to interpretation of changes in context of molecular pathways when two "interacting" genes are actually not expressed in the same cell type could also occur. Results of other groups and our own results indicate differences in responses to hormonal control and signals of the embryo in specific endometrial compartments. For example, a comparison of two microarray studies of similar stages of cyclic endometrium (Day 7 vs. Day 14) using the same Affymetrix bovine microarray (Salilew-Wondim et al. 2010, Forde et al. 2011a) revealed a very small overlap, not higher than expected by chance. This finding strongly indicates cell type-specific gene expression changes in the bovine endometrium during the estrous cycle since different sampling techniques were used in these studies, whole endometrial tissue samples in Forde et al. (2011a) and cytobrush samples in Salilew-Wondim et al. (2010). Cytobrush samples mainly contain cells of the luminal surface, i.e. LE and superficial GE. A second example is a study of equine endometrial biopsy samples where one sample was found to have a strong deviation in the percentage of LE cells which resulted in distinct differences in gene expression (Merkl et al. 2010). The only way to overcome this issue will be the separate analysis of endometrial cell types by the use of laser capture microdissection for the collection of samples from distinct 
endometrial compartments. Although the separate analysis of different endometrial cell types would considerably increase the complexity of transcriptome studies, it should be feasible using most current RNA-Seq technologies.

Additional approaches to identify new genes or pathways important for endometrial functions in context of establishment and maintenance of pregnancy could be the analysis of endometrial transcriptomes across different mammalian species (Bauersachs \& Wolf 2012) and an extension of transcriptomics data with proteomics, e.g., the systematic analysis of uterine secretions during the preimplantation phase (Forde et al. 2014).

\section{Conclusions}

The comparison of transcriptome studies in bovine endometrium during the preimplantation phase showed consistent gene expression changes, particularly for the genes upregulated in pregnant endometrium. This is in contrast to microarray studies performed for human endometrium (Riesewijk et al. 2003). The overlap between studies was lower for downregulated genes, which could be due to different reasons, e.g., higher variation of gene expression values obtained for these genes in whole endometrial tissue samples, a temporal regulation of these genes, and hormonal differences in the cyclic control animals, particularly for the later time points. The combined analysis of the summarized studies provides a more complete picture of gene expression changes during the preimplantation phase and, in addition, for the comparison to other mammals as shown in a comparison to porcine endometrium.

\section{Supplemental data}

Supplemental data can be downloaded via: https://polybox.ethz.ch/public.php?service = files $\& \mathrm{t}=1 \mathrm{a} 46 \mathrm{ddd} 3942 \mathrm{~d} 7 \mathrm{ecd} 93481 \mathrm{fd} 9 \mathrm{a} 6 \mathrm{bb} 4439$

\section{Acknowledgements}

The generation of data analyzed in this study was supported by the German Ministry for Education and Research (BMBF, FUGATO-plus, COMPENDIUM; FUGATO Fertilink) and the German Research Foundation (DFG FOR478). The author is part of the European Union COST action FA1201 Epiconcept.

\section{References}

Bauersachs S \& Wolf E 2012 Transcriptome analyses of bovine, porcine and equine endometrium during the pre-implantation phase. Animal Reproduction Science 134 84-94.

Bauersachs S, Ulbrich SE, Gross K, Schmidt SE, Meyer $\mathbf{H H}$, Wenigerkind $\mathbf{H}$, Vermehren $M$, Sinowatz $F$, Blum H \& Wolf E 2006 Embryo-induced transcriptome changes in bovine endometrium reveal speciesspecific and common molecular markers of uterine receptivity. Reproduction 132 319-331.

Bauersachs S, Ulbrich SE, Reichenbach HD, Reichenbach M, Buttner M, Meyer HH, Spencer TE, Minten M, Sax
G, Winter G \& Wolf E 2012 Comparison of the effects of early pregnancy with human interferon, alpha 2 (IFNA2), on gene expression in bovine endometrium. Biology of Reproduction 8646.

Bazer FW, Burghardt RC, Johnson GA, Spencer TE \& Wu G 2008 Interferons and progesterone for establishment and maintenance of pregnancy: interactions among novel cell signaling pathways. Reproductive Biology 8 179-211.

Bazer FW, Spencer TE \& Johnson GA 2009 Interferons and uterine receptivity. Seminars in Reproductive Medicine 27 90-102. 
Clemente M, de La Fuente J, Fair T, Al Naib A, GutierrezAdan A, Roche JF, Rizos D \& Lonergan P 2009 Progesterone and conceptus elongation in cattle: a direct effect on the embryo or an indirect effect via the endometrium? Reproduction 138 507-517.

Dorniak P, Bazer FW \& Spencer TE 2013 Physiology and Endocrinology Symposium: biological role of interferon tau in endometrial function and conceptus elongation. Journal of Animal Science 91 1627-1638.

Eun Kwon H \& Taylor HS 2004 The role of HOX genes in human implantation. Annals of the New York Academy of Sciences 1034 1-18.

Forde N \& Lonergan P 2012 Transcriptomic analysis of the bovine endometrium: What is required to establish uterine receptivity to implantation in cattle? Journal of Reproduction and Development 58 189-195.

Forde N, Carter F, Fair T, Crowe MA, Evans AC, Spencer TE, Bazer FW, McBride R, Boland MP, O'Gaora P, Lonergan P \& Roche JF 2009 Progesterone-regulated changes in endometrial gene expression contribute to advanced conceptus development in cattle. Biology of Reproduction 81 784-794.

Forde N, Beltman ME, Duffy GB, Duffy P, Mehta JP, O'Gaora P, Roche JF, Lonergan P \& Crowe MA 2011a Changes in the endometrial transcriptome during the bovine estrous cycle: effect of low circulating progesterone and consequences for conceptus elongation. Biology of Reproduction 84 266-278.

Forde N, Carter F, Spencer TE, Bazer FW, Sandra O, Mansouri-Attia N, Okumu LA, McGettigan PA, Mehta JP, McBride R, O'Gaora P, Roche JF \& Lonergan P 2011 b Conceptus-induced changes in the endometrial transcriptome: how soon does the cow know she is pregnant? Biology of Reproduction 85 144-156.

Forde N, Duffy GB, McGettigan PA, Browne JA, Mehta JP, Kelly AK, Mansouri-Attia N, Sandra O, Loftus BJ, Crowe MA, Fair T, Roche JF, Lonergan P \& Evans AC 2012 Evidence for an early endometrial response to pregnancy in cattle: both dependent upon and independent of interferon tau. Physiological Genomics 44 799-810.

Forde N, McGettigan PA, Mehta JP, O'Hara L, Mamo S, Bazer FW, Spencer T \& Lonergan P 2014 Proteomic analysis of uterine fluid during the pre-implantation period of pregnancy in cattle. Reproduction 147 575-587

Geisert RD, Fox TC, Morgan GL, Wells ME, Wettemann RP \& Zavy MT 1991 Survival of bovine embryos transferred to progesterone-treated asynchronous recipients. Journal of Reproduction and Fertility 92 475-482.

Johnson GA, Bazer FW, Jaeger LA, Ka H, Garlow JE, Pfarrer C, Spencer TE \& Burghardt RC 2001 Muc1 , integrin, and osteopontin expression during the implantation cascade in sheep. Biology of Reproduction 65 820-828.

Klein C, Bauersachs S, Ulbrich SE, Einspanier R, Meyer HH, Schmidt SE, Reichenbach HD, Vermehren M, Sinowatz F, Blum H \& Wolf E 2006 Monozygotic twin model reveals novel embryo-induced transcriptome changes of bovine endometrium in the preattachment period. Biology of Reproduction 74 253-264.
Ledgard AM, Berg MC, McMillan WH, Smolenski G \& Peterson AJ 2012 Effect of asynchronous transfer on bovine embryonic development and relationship with early cycle uterine proteome profiles. Reproduction, Fertility, and Development 24 962-972.

Magli MC, Largman C \& Lawrence HJ 1997 Effects of HOX homeobox genes in blood cell differentiation. Journal of Cellular Physiology 173 168-177.

Merkl M, Ulbrich SE, Otzdorff C, Herbach N, Wanke R, Wolf E, Handler J \& Bauersachs S 2010 Microarray analysis of equine endometrium at days 8 and 12 of pregnancy. Biology of Reproduction 83 874-886.

Minten MA, Bilby TR, Bruno RG, Allen CC, Madsen CA, Wang Z, Sawyer JE, Tibary A, Neibergs HL, Geary TW, Bauersachs S \& Spencer TE 2013 Effects of fertility on gene expression and function of the bovine endometrium. PloS One 8 e69444.

Popovici RM, Krause MS, Germeyer A, Strowitzki T \& von Wolff M 2005 Galectin-9: a new endometrial epithelial marker for the mid- and late-secretory and decidual phases in humans. The Journal of Clinical Endocrinology and Metabolism 90 6170-6176.

Riesewijk A, Martin J, van Os R, Horcajadas JA, Polman J, Pellicer A, Mosselman S \& Simon C 2003 Gene expression profiling of human endometrial receptivity on days $\mathrm{LH}+2$ versus $\mathrm{LH}+7$ by microarray technology. Molecular Human Reproduction 9 253-264.

Salilew-Wondim D, Holker M, Rings F, Ghanem N, UlasCinar M, Peippo J, Tholen E, Looft C, Schellander K \& Tesfaye D 2010 Bovine pretransfer endometrium and embryo transcriptome fingerprints as predictors of pregnancy success after embryo transfer. Physiological Genomics 42 201-218.

Samborski A, Graf A, Krebs S, Kessler B \& Bauersachs S 2013a Deep sequencing of the porcine endometrial transcriptome on day 14 of pregnancy. Biology of Reproduction 8884.

Samborski A, Graf A, Krebs S, Kessler B, Reichenbach M, Reichenbach HD, Ulbrich SE \& Bauersachs S 2013b Transcriptome changes in the porcine endometrium during the preattachment phase. Biology of Reproduction 89134.

Satterfield MC, Song G, Hayashi K, Bazer FW \& Spencer TE 2008 Progesterone regulation of the endometrial WNT system in the ovine uterus. Reproduction, Fertility, and Development 20 935-946.

Spencer TE \& Bazer FW 2002 Biology of progesterone action during pregnancy recognition and maintenance of pregnancy. Frontiers in Bioscience 7 d1879-1898.

Spencer TE, Johnson GA, Bazer FW \& Burghardt RC 2004 Implantation mechanisms: insights from the sheep. Reproduction. 128 657-668.

Spencer TE, Johnson GA, Bazer FW \& Burghardt RC 2007 Fetal-maternal interactions during the establishment of pregnancy in ruminants. Society of Reproduction and Fertility supplement 64 379-396.

Subramanian A, Kuehn H, Gould J, Tamayo P \& Mesirov JP 2007 GSEA-P: a desktop application for Gene Set Enrichment Analysis. Bioinformatics 23 3251-3253.

Thatcher WW, Hansen PJ, Gross TS, Helmer SD, Plante C \& Bazer FW 1989 Antiluteolytic effects of bovine 
trophoblast protein-1. Journal of Reproduction and Fertility Supplement 37 91-99.

Ulbrich SE, Groebner AE \& Bauersachs S 2013 Transcriptional profiling to address molecular determinants of endometrial receptivity-lessons from studies in livestock species. Methods $\mathbf{5 9}$ 108-115.

Venhoranta H, Bauersachs S, Taponen J, Lohi H, Taira T, Andersson M, Kind A, Schnieke A \& Flisikowski K 2013 Fetal growth restriction caused by MIMT1 deletion alters brain transcriptome in cattle. International Journal of Developmental Neuroscience 31 463-467.

Volpe MV, Ramadurai SM, Pham LD \& Nielsen HC 2007 Hoxb-5 down regulation alters Tenascin-C, FGF10 and Hoxb gene expression patterns in pseudoglandular period fetal mouse lung. Frontiers in Bioscience 12 860-873.

Walker CG, Meier S, Littlejohn MD, Lehnert K, Roche JR \& Mitchell MD 2010 Modulation of the maternal immune system by the pre-implantation embryo. BMC Genomics 11474.

Wang Y, Hanifi-Moghaddam P, Hanekamp EE, Kloosterboer HJ, Franken P, Veldscholte J, van Doorn HC, Ewing PC, Kim JJ, Grootegoed JA, Burger CW, Fodde R \& Blok LJ 2009 Progesterone inhibition of $\mathrm{Wnt} /$ beta-catenin signaling in normal endometrium and endometrial cancer. Clinical Cancer Research 15 5784-5793. 
